\title{
Mulemba
}

Revista Angolana de Ciências Sociais

6 (11) | 2016

Políticas, direitos e práticas da sociedade e do Estado

\section{A política de água em Angola: Algumas notas sobre os abastecimentos de água em Luanda e Benguela}

Water policy in Angola: Some notes on water supplies in Luanda and Benguela

\section{Fernando Paulo Faria}

\section{(2) OpenEdition \\ 12 Journals}

\section{Edição electrónica}

URL: http://journals.openedition.org/mulemba/1314

DOI: 10.4000/mulemba.1314

ISSN: 2520-0305

\section{Editora}

Edições Pedago

\section{Edição impressa}

Data de publição: 1 maio 2016

Paginação: 57-83

ISSN: 2182-6471

\section{Refêrencia eletrónica}

Fernando Paulo Faria, «A política de água em Angola: Algumas notas sobre os abastecimentos de água em Luanda e Benguela», Mulemba [Online], 6 (11) | 2016, posto online no dia 01 outubro 2018, consultado o 26 janeiro 2021. URL: http://journals.openedition.org/mulemba/1314 ; DOI: https:// doi.org/10.4000/mulemba.1314 


\title{
A política de água em Angola: Algumas notas sobre os abastecimentos de água em Luanda e Benguela
}

\author{
Fernando Paulo Faria*
}

\begin{abstract}
Resumo: As questões da água e do saneamento são dois temas actuais que constam da agenda política como dois dos muitos problemas ainda pendentes por resolver em Angola, apesar de haver passado cerca de 39 anos depois da proclamação da sua independência. Para acentuar a contradição, o país é possuidor de um enorme potencial hídrico em África, só superado pelo seu vizinho, a República Democrática do Congo. ${ }^{1}$ Todavia, os cerca de 27 anos de guerra civil que assolou o país apresentam-se como um factor explicativo quando se questionam os motivos pelos quais a água e o saneamento básico continuam a ser dois dos maiores problemas públicos e sociais em Angola. O peso deste factor, objectivamente não depreciável, torna-se ainda maior, e quase exclusivo, quando as explicações provêm dos gabinetes governamentais. Contudo, estes factores não podem explicar o problema de forma generalizada, se tivermos em conta que em Benguela a gestão da água é mais eficiente do que a de Luanda. Ao longo da história, o progresso humano dependeu do acesso à água e da capacidade das sociedades em aproveitar o seu potencial como recurso produtivo. Esta realidade perene continua actual no mundo de hoje, pois entre as bases para o desenvolvimento humano destacam-se a água para a vida no seio das famílias e a água destinada aos meios de sustento através da produção. Mas, para uma grande parte da humanidade - e isso é válido para o caso de Angola -, tal como asseguram os últimos relatórios do PNUD - Programa das Nações Unidas para o Desenvolvimento, essas bases ainda não se estabeleceram. Angola enfrenta ingentes desafios, a julgar pelos múltiplos problemas de acesso à água potável e ao saneamento adequado, com que se defronta uma importante percentagem da sua população, com todas as consequências disso decorrente, na saúde pública e no bem-estar. Constituindo um resumo da nossa tese de doutoramento, o presente texto tem como base o estudo sobre a governança da água que aí desenvolvi, centrando-se em duas dimensões:
\end{abstract}

* Politólogo. Professor Auxiliar, Chefe do Departamento de Ciência Política (DCP), Coordenador da «Série Ciência Política» dos Cadernos de Ciências Sociais e membro do Conselho Científico-Pedagógico ( $\mathrm{ccP}$ ) da Faculdade de Ciências Sociais (FCS) da Universidade Agostinho Neto (UAN).

1 Os dois países representam pouco mais de $25 \%$ do potencial hídrico do continente africano. 
o abastecimento urbano e o saneamento, em que se procurou descrever e explicar a política de água no país (1975-2014), comparando o seu impacto em duas das suas mais importantes províncias (Luanda e Benguela), que na tese foram tomadas como unidades ilustrativas da política de água de Angola. Uma das conclusões do estudo diz que, por um lado, Angola ao longo da sua curta trajectória de política hidráulica (ainda não consolidada), caracterizou-se por um modelo de oferta; por outro lado, concluiu-se que apesar de partilharem o mesmo quadro institucional e legal a que estão sujeitas, o quadro comparativo entre as estruturas de gestão da água nas duas províncias revela que, devido a factores diversos, em Benguela, a distribuição de água apresenta-se de modo mais eficiente em relação ao de Luanda.

Palavras-chave: Governança da água, políticas públicas, abastecimentos urbanos, saneamento básico, Luanda, Benguela.

\section{Introdução}

A água é o elemento mais frequente na terra, mas cerca de $97,5 \%$ da água do planeta é água salgada dos mares e oceanos, apenas $2,5 \%$ é água doce, mas esta percentagem não se encontra totalmente disponível, pois, 2/3 desta água encontra-se imobilizada nos glaciares e em neves perpétuas. Os recursos de água doce se vêm ainda reduzidos pela contaminação, um problema que afecta não só os países em desenvolvimento, mas também os países mais industrializados. Por outro lado a disponibilidade global da água em relação a população revela disparidades continentais. ${ }^{2}$ Esta realidade natural vem desde algum tempo despertando o alarme mundial.

Desde as primeiras conferências das Nações Unidas sobre o meio ambiente (1972), ${ }^{3}$ foi ficando evidente que a problemática da água reveste-se de um interesse comum e um valor relevante nos conceitos de desenvolvimento e sustentabilidade ambiental. Estes fóruns

2 O continente asiático, com mais da metade da população mundial, possui cerca de $36 \%$ dos recursos hídricos do Mundo; África, com 13\% da população, alberga $11 \%$ dos recursos hídricos; Europa, igualmente com 13\% da população, tem apenas $8 \%$ dos recursos hídricos e América, com $14 \%$ da população mundial, guarda $43 \%$ dos recursos hídricos.

3 A Conferência das Nações Unidas sobre o Meio Humano de 1972, marcou o início de uma série de actividades globais em torno da água; não obstante esse facto, foi apenas na Conferência de Mar del Plata que se enfatiza a preocupação pela eficiência da água, seguindo-se-lhe o Decénio Internacional de Água e Saneamento (1981-1990). Todavia, dadas as preocupações acentuadas em cada um desses eventos, os encontros mundiais tendentes a discutir as questões da água tenderam a multiplicarem-se, sobretudo a partir de 2000 , aquando da realização do $2 .{ }^{\circ}$ Forum Mundial da Água. 
foram instando aos países para adopção de políticas públicas em matéria de água.

Historicamente, a água foi sempre uma fonte de conflitos, por este facto, o estabelecimento de acordos de cooperação em torno a água remontam a civilizações antigas como a Egípcia ou a Mesopotâmica (BEnÉt e Masagué 1986).

Nas últimas décadas, os estudos sobre a água têm centrado o interesse de muitos investigadores sociais dado os indícios da sua escassez no início deste século. A enorme preocupação a nível internacional pode comprovar-se se olharmos nas ultimas duas décadas, a quantidade de eventos mundiais sobre a água que se realizaram para debater o problema e a grande constatação destes eventos sobre a água permite sustentar que embora a humanidade tem vindo a enfrentar neste terceiro milénio diversos desafios, quer sejam de ordem social ou relativo aos recursos naturais, a crise da água é a que se encontra no centro da sobrevivência mundial, segundo o primeiro informe sobre o desenvolvimento dos recursos hídricos no mundo (WWDR 2000). Por outro lado, estes fóruns permitiram concluir, que a questão da crise não se centra fundamentalmente na sua escassez, ou na sua localização assimétrica mas trata-se sobretudo de uma crise de gestão dos recursos hídricos ou dito de outro modo, uma crise de governança da água. E os efeitos desta crise de gestão da água são maiores nas populações dos países em desenvolvimento, pois são essas que sofrem o peso das doenças relacionadas com a água, os problemas do saneamento, o fraco acesso aos recursos energéticos, etc.

Em pouco mais de 35 anos de debate sobre a problemática da água e do saneamento ao nível internacional, cabe destacar a Conferencia do Milénio (2000) organizada pelas Nações Unidas em New York, que estabeleceu os objectivos de desenvolvimento do milénio, realçando aqui a meta $7 \mathrm{C}$ que se propõe «reduzir para a metade até ao ano 2015, a percentagem das pessoas sem acesso sustentável a água potável e ao saneamento».

$\mathrm{O}$ trabalho que teve como base o presente texto inspirou-se em aquelas premissas que consideram a crise da água como principalmente uma crise de governança. Por conseguinte, a política e o sistema institucional sobressaem como instrumentos decisivos (ou condição estrutural) para superar ou perpetuar os problemas de gestão da água. 


\section{Marco teórico da investigação}

O marco teórico que suportou a nossa investigação, desenvolveuse a partir da perspectiva sobre o manejo da água desde um enfoque de governança, entendido desde a perspectiva conceptual de Hanf e Jansen (1998), os quais enfatizam a sua concepção de governança essencialmente como um processo e não tanto como um estado que haveria de alcançar-se. Neste sentido a governança da água corresponderia a configuração e manutenção do exercício de autoridade e do poder dentro dos quais novos actores podem participar no processo de tomada de decisões encaminhadas a lograr um benefício comum. Em base a essa concepção de governança da água, a explicação sobre o problema da água em Angola há-de buscar-se no processo político responsável pela configuração do sistema institucional da gestão da água desde a independência do país, seu estado de desenvolvimento e sua capacidade de funcionamento.

Todavia a abordagem sobre o papel do sistema institucional responsável pela gestão da água não pode desenvolver-se fora do contexto mas amplo das abordagens institucionais amparadas nas diversas perspectivas institucionalistas desenvolvidas a partir da Ciência Política. Neste sentido para entender o êxito e fracassos das políticas adoptadas pelo Estado baseamo-nos nos argumentos de Evans (1995) sobre o papel do Estado (na qual ressalta a capacidade burocrática) na promoção do desenvolvimento e da boa governação. Desde aqui propusemos o edifício conceptual onde se desenvolveu o estudo posterior sobre a governança da água em Angola.

A capacidade institucional do Estado na promoção do desenvolvimento (sobretudo em países em desenvolvimento como Angola) constitui um tema recorrente nas últimas décadas, nas abordagens teóricas sobre Políticas Públicas. A partir dos enfoques neo-institucionalistas encabeçados por Evans, bem como das contribuições teóricas de autores como Ronald Coase, Douglass North, Menard e Shirley, construiu-se a preposição de que os estados podem ser «desenvolvimentistas» se são capazes de fomentar as perspectivas de longo prazo das elites privadas, de ajudar a solucionar problemas de acção colectiva e cobrir investimentos essenciais na educação e infra-estruturas, em base a duas condições estructurais: Em primeiro lugar a promoção de uma burocracia capacitada e em segundo lugar, a inserção do projecto governamental nas ambições e possibilidades das empresas e da sociedade. Em definitivo, o Estado deve manter uma 
teia densa de vínculos com grupos sociais fora dele a fim de construir um projecto de transformação conjunto, mas mantendo uma certa autonomia em relação a estes mesmos grupos sociais, para que não actue como seu agente. Portanto o argumento de Evans (1995) considera chave manter o equilíbrio entre autonomia do Estado e parceria ou inserção, cujo sucesso dependeria da contínua reconstrução da relação entre Estado e Sociedade.

Por outro lado, as contribuições de North (1990) sobre as instituições e o desenvolvimento económico bem como o contraste dos seus argumentos com a evidência empírica que representavam o fracasso das políticas de ajuste estrutural, fizeram renascer o novo paradigma de que as instituições são a chave do desenvolvimento económico dos Estados. Mas de que instituições nos referimos? O argumento que sustenta a nossa investigação situa-se ao lado daquelas que consideram que o factor chave para o desenvolvimento, são as instituições políticas que promovem a «boa governação» sendo as perspectivas de good governance defendida por autores como Kaufmann, Mastruzzi, Kraay entre outros.

Na base do estudo sobre o processo de elaboração de politicas publicas em que se enquadra nosso trabalho, a visão da relação e cooperação que propõe Evans, torna-se necessária, sobretudo quando se reconhece que pese a sobre valoração (desde alguns sectores) de factores como a distribuição irregular da água no mundo, os factores climáticos e a pressão demográfica, enquanto responsáveis pela crise mundial da água, todavia há que reconhecer-se que dita crise comporta uma explicação política importante e como tal o sistema institucional responsável pela gestão da água.

Ao analisarmos o papel da burocracia estatal nos países em desenvolvimento e sua influência nos resultados das políticas, considerase que no mundo contemporâneo, ademais das funções clássicas assente na defesa e na diplomacia, espera-se que o Estado seja capaz de promover a transformação económica e com ele garantir níveis mínimos de bem-estar social.

No caso de África, a maioria dos Estados representavam um verdadeiro drama para as enormes expectativas dos cidadãos em relação ao período pós-colonial. O funcionamento destes Estados representavam um desafio não apenas para os cidadãos mas também para as próprias teorias, pois uma analise as suas estruturas internas, em nada se pareciam a uma burocracia no sentido weberiano, muito menos sua relação com a sociedade comportava as características 
defendidas por Evans em base aos seus argumentos institucionais aludidos anteriormente. No entanto, na nova agenda para o desenvolvimento de África, proposto pelas Nações Unidas em 1991, pode-se constatar entre os pressupostos básicos para good governance, o desenvolvimento institucional e a reforma do sector público como componentes cruciais para o desenvolvimento.

Angola segue nesta mesma lógica, pois, desde as últimas décadas vem tentando implementar uma série de iniciativas de reformas da administração pública. Neste sentido, em 1996, com o apoio do PNUD - Programa das Nações Unidas para o Desenvolvimento, criou o programa de reforma institucional e modernização administrativa (PRIMA), e em 1999, lançou o programa de reforma administrativa (PREA), cujos objectivos centravam-se na melhoria dos serviços públicos mediante a descentralização e modernização da administração pública. Mais tarde, em 2002, foi criado o programa de reforço institucional da administração pública (REFORPA) financiado pelo governo de Itália, por intermédio da ONU (UNDESA). Todos estes programas de reforma do sector público constituem um desafio de médio/longo prazo, tendo como objectivo central apostar na melhoria da capacidade do Estado com vista a tornar a sua actuação mais eficaz na resolução dos assuntos da colectividade. A reforma e modernização do Estado e suas instituições, apresenta-se como condição sine qua non para que Angola alcance o desenvolvimento sustentável. A partir daqui se basearam as premissas que sustentam o nosso modelo de análise.

Conforme já aludimos em parágrafos anteriores, Evans (2004) focaliza a sua análise na função do Estado em fomentar o crescimento económico mediante o desenvolvimento da indústria local (Brasil) das tecnologias de informação (ТI). Desde os seus argumentos, construímos uma base explicativa para entender a preponderância do Estado em promover o desenvolvimento em outras áreas ou âmbitos das políticas e assegurar o bem-estar da colectividade, como é o caso da governança da água. Pois, compreender as estruturas e o papel do Estado e suas relações com a sociedade e como o Estado contribui para o desenvolvimento, constitui nosso ponto de partida para entender o que se passa em Angola com a política de água particularmente. Dizemos particularmente porque o argumento explicativo que se alude pode servir para compreender a situação do país em todas suas dimensões, se termos em consideração que os problemas de Angola (nesta fase de reconstrução) não se resumem apenas com o manejo ou gestão da água, mas também em outras esferas da 
sociedade (educação, saúde, desenvolvimento industrial, desemprego, pobreza, etc.). Isto equivale dizer que considerando a premissa de que o Estado encontra-se no centro das soluções dos problemas da colectividade, a compreensão da realidade sobre a política da água em Angola, só é possível mediante uma visão mais ampla acerca da estrutura organizacional sustentada pelo Estado e da sua capacidade na provisão de serviços e bens colectivos como a água, saneamento, estradas, escolas, hospitais, etc. e ser ainda capaz de actuar como um instrumento redistributivo.

\section{Objecto e metodologia da investigação}

Nossa investigação se contextualiza dentro daquelas que centram sua atenção nas causas, no conteúdo e nas consequências da actuação do Estado. «O processo de actuação pública é o conjunto complexo de acontecimentos que determinam as medidas que adoptarão os governos e os efeitos que estas produzem nas condições sociais» (MANnheim et al, 1998: 429). E como tal, aplicaram-se na nossa investigação determinados instrumentos e técnicas de análises de políticas públicas, nas quais se destacam:

1. ${ }^{\circ}$ A análise de correlatos;

2. ${ }^{\circ}$ A análise institucional;

$3 .^{\circ}$ A análise do impacto.

O primeiro enfoque procura explicar por que as diferentes cidades, nos casos concretos de Luanda e Benguela, nas suas estruturas de gestão se podem constatar actuações distintas, explorando a relação entre ambas e as características politicas, sociais, demográficas e económicas das duas unidades. A análise institucional como segundo enfoque, investiga os papéis que jogam as instituições políticas na definição das políticas a adoptar e o modo de sua implementação. Finalmente o terceiro enfoque tem por objecto, analisar os resultados que realmente produzem as políticas. Partindo destas premissas, a investigação toma como objecto de estudo a política de água em Angola, analisando em particular os seus resultados em Luanda e Benguela.

A pertinência do estudo reside no facto de que ademais da sua relevância académica, o estudo atende também a uma necessidade 
social na medida em que as questões da água e do saneamento constituem dois dos mais graves problemas sociais que enfrenta o pais.

A selecção de Luanda e Benguela entre as 18 províncias de Angola como unidades de estudo, justifica-se por diversas razões: Sua importância política, económica, demográfica e social. Ademais são as duas províncias com maiores volumes de investimento publico no sector das águas e saneamento, investimentos estes que incrementaram-se nos últimos anos, particularmente desde 2002.

A investigação enquadra-se no modelo metodológico «interpretativo ou construtivista» onde predominaram essencialmente as técnicas de análises de investigação qualitativas.

Entre as distintas técnicas de investigação qualitativas, a nossa investigação baseou-se principalmente na análise de documentos e nas entrevistas em profundidade para a comprovação das hipóteses, sem esquecer o método comparativo que nos permitiu comparar os resultados da política da água e saneamento nas províncias de Luanda e Benguela.

\subsection{As unidades do estudo}

Luanda e Benguela constituem dois casos que pretendemos sejam ilustrativos da política de água em Angola.

Luanda é a capital política, o maior centro económico e a cidade mais populosa de Angola, ao passo que Benguela é uma importante cidade do litoral, constitui a segunda maior concentração urbana do país. Ao contrário da maioria das províncias do país, ambas possuem um modelo empresarial de gestão da água e do saneamento.

Por outro lado, Benguela embora não tenha sido das províncias mais fustigadas pela guerra que assolou o país, todavia foi mais directamente afectada quando comparada com Luanda (que era de longe a cidade mais segura durante a guerra). Isso é particularmente importante já que a degradação dos sistemas de distribuição e outras infra-estruturas hidráulicas tem como causas não só a sua antiguidade como também os efeitos do conflito armado tendo afectado obviamente a sua capacidade de funcionamento, com incidência nos níveis de cobertura de água.

A entidade pública gestora dos sistemas de água em Luanda é a Empresa Provincial de Água de Luanda (EPAL). Conta com um total de 5 estações de tratamento que se desenvolve ao largo de $132 \mathrm{~km}$ 
de condutas adutoras e 3.180km de rede de distribuição, com uma capacidade nominal actual de $488.800 \mathrm{~m}^{3} /$ dia e uma capacidade de reserva em torno aos $160600 \mathrm{~m}^{3} /$ dia (EPAL 2012). O quadro abaixo resume a situação actual de funcionamento dos sistemas de produção de água em Luanda.

Quadro 1. Rendimento dos sistemas de abastecimento de água de Luanda

\begin{tabular}{l|l|l|l}
\hline Sistemas & $\begin{array}{l}\text { Capacidade } \\
\text { instalada } \\
\left(\mathbf{m}^{3} / \mathbf{d i a}\right)\end{array}$ & $\begin{array}{l}\text { Produção } \\
\text { real }\left(\mathbf{m}^{3} / \mathbf{d i a}\right)\end{array}$ & $\begin{array}{l}\text { Rendimento } \\
\mathbf{( \% )}\end{array}$ \\
\hline Sistema 1 & 60 ooo & 36169 & 60,28 \\
\hline Sistema 2 & 138000 & 103411 & 74,94 \\
\hline Sistema 3 & 216000 & 121386 & 56,20 \\
\hline Sistema Kikuxi & 17200 & 12065 & 70,15 \\
\hline Sistema Luanda Sul & 57600 & 26108 & 45,33 \\
\hline TOTAL & $\mathbf{4 8 8 ~ 8 0 0}$ & $\mathbf{2 9 9 . 1 3 8}$ & $\mathbf{6 1 , 2 0}$ \\
\hline
\end{tabular}

Fonte: EPAL-EP (2011)

A responsabilidade na gestão dos sistemas de produção, abastecimento e o saneamento das águas residuais em toda a área metropolitana de Benguela esta conferida a duas empresas públicas, por um lado a Empresa de Água e Saneamento de Benguela (EASB), criada em 1995, e por outro, a Empresa de Água e Saneamento do Lobito (EASBL), criada em $1988 .^{4}$

Considerando que a zona metropolitana de Benguela está composta por quatro cidades principais, cada uma das duas empresas tem a seu cargo uma área de jurisdição. Assim a EASB tem responsabilidades de captação, tratamento e distribuição da água e do saneamento das águas residuais nos municípios de Benguela (cidade) e Baía Farta, ao passo que a EASBL tem as mesmas responsabilidades nos municípios do Lobito e Catumbela. Nos restantes municípios da província a responsabilidade dos serviços de água e saneamento está a cargo das respectivas administrações municipais que contam com a supervisão e direcção da Direcção Provincial de Energia e Águas (DPEA).

4 Embora as duas empresas estejam em funcionamento há pouco mais de 20 anos, todavia a sua existência formal é muito recente, ou seja desde 2012, quando foi aprovado por despacho conjunto do Ministro da Economia e da Energia e Águas as suas estruturas orgânicas. 
Actualmente a capacidade instalada na totalidade dos seus 5 grandes sistemas de produção em funcionamento é de 130205 m3/dia (no entanto a capacidade real situa-se nos $60000 \mathrm{~m}^{3} / \mathrm{dia}$ ). Segundo dados da EASB (2013), a cidade conta com um total de $320 \mathrm{~km}$ de rede. O quadro abaixo resume a situação do funcionamento dos sistemas de produção de água em Benguela.

Quadro 2. Sistemas de produção de água de Benguela

\begin{tabular}{|c|c|c|c|}
\hline Cidade atendida & Rio & $\begin{array}{l}\text { Denominação } \\
\text { do sistema }\end{array}$ & $\begin{array}{l}\text { Produção } \\
\text { em } \mathbf{m}^{3} / \text { dia }\end{array}$ \\
\hline
\end{tabular}

I - Sistema existente

\begin{tabular}{l|l|l|l}
\hline Lobito & Catumbela & Campo de poços Chiule & 23069 \\
\hline Benguela & Cavaco & Antigo Campo de poços & 1680 \\
\cline { 2 - 4 } & & Novo Campo de poços A & 16464 \\
\hline Baía Farta & Cavaco & Novo Campo de poços A & 2592 \\
\hline \multicolumn{2}{|c}{ TOTAL } & 43805 \\
\hline
\end{tabular}

II - Sistema projectado

\begin{tabular}{l|l|l|l}
\hline Lobito & Catumbela & ETA integrada & 60480 \\
\cline { 1 - 2 } Benguela & & 25920 \\
\hline \multicolumn{2}{c|}{ TOTAL } & 86400 \\
\hline \multicolumn{2}{c|}{ Produção total } & 130205 \\
\hline
\end{tabular}

Fonte: Elaboração do Autor com base nos dados da EASB (2013)

\section{Perspectiva geral do problema da água: África e SADC}

\subsection{Situação africana}

O problema da água no continente africano situa-se dentro do contexto da problemática da água doce no Mundo. O continente enfrenta uma multitude de problemas socioeconómicos que reclamam soluções urgentes para inverter as tendências actuais de um subdesenvolvimento quase generalizado e de pobreza. E o papel crucial da água na realização das tarefas para alcançar as metas do desenvolvimento e combater a pobreza é hoje amplamente reconhecido.

Dentro do marco de iniciativas endógenas para debater o problema e recomendar soluções, cabe destacar a elaboração de um documento 
denominado «Africa Water Vision 2025» uma elaboração conjunta de várias organizações africanas com a colaboração do Banco Mundial. A visão foi desenvolvida para servir a duas funções: Por um lado como instrumento de desenvolvimento socioeconómico em África e por outro, como parte integrante de una iniciativa a escala global para desenvolver uma visão mundial da água.

Este documento foi também adoptado como guia de orientação (por parte da própria União Africana através do seu Conselho de Ministros da Água criado em 2002, bem como da Associação Africana da Água criado em 2012), para orientar aos países africanos a adopção de políticas que permitam que o potencial africano em recursos hídricos seja libertado para estimular e sustentar o desenvolvimento socioeconómico e promover o bem-estar social do povo africano. Todavia reconhece-se amplamente que estes logros só se podem conseguir se são introduzidas reformas ou mudanças nas actuais formas de gestão dos recursos hídricos, seja a nível nacional ou a nível das organizações sub-regionais africanas encabeçadas pela União Africana.

As potencialidades hídricas do continente impelem a um certo optimismo, pois, a relação entre disponibilidade de água e população é de $11 \%$ para $13 \%$, no entanto há uma série de factores que ameaçam sua sustentabilidade: ${ }^{5}$

1. ${ }^{\circ}$ A multiplicidade de Bacias Hidrográficas partilhadas que podem gerar conflitos entre Estados em um contexto caracterizado por uma débil legislação internacional sobre águas e uma escassa cooperação sobre questões de qualidade e quantidade de água.

$2{ }^{\circ}$ A governação e reforma institucional inadequada na gestão de Bacias sejam nacionais e transnacionais.

$3 .{ }^{\circ}$ Limitações financeira, que impede a realização de investimentos adequados para a avaliação, protecção e desenvolvimento dos recursos hídricos africanos.

Estas ameaças representam para os países africanos individualmente e para as organizações sub-regionais a que pertencem colectivamente, importantes desafios na gestão dos recursos hídricos do continente.

5 Estes factores foram apontados em um documento intitulado África Water Vision 2025, elaborado conjuntamente pela Comissão Económica para África (CEA), União Africana (UA) e pelo Banco Africano de Desenvolvimento (BAD). 
África é um continente com grandes disparidades na disponibilidade de água entre sub-regiões, entre países, mas também com disparidades dentro de um mesmo país. Por exemplo a região do norte de África recebe $9 \%$ do total das precipitações da região, África Austral cerca de $12 \%$ ao passo que a Bacia do Congo recebe $35 \%$ albergando $10 \%$ da população do continente. A disparidade na disponibilidade entre países provoca que a República Democrática do Congo (RDC), o país mais húmido da região concentre $935 \mathrm{~km}^{3}$, o que representa cerca de $25 \%$ do total da água da região, enquanto Mauritânia o país mais seco apenas dispõe de $0,4 \mathrm{~km}^{3}$ cerca 0,01 do total da água em África (PNUMA 2002).

No que concerne aos abastecimentos de água e saneamento em África há duas realidades. Os piores indicadores encontram-se entre os países da zona subsaariana, pois se em 1990 a percentagem da população que utilizava uma fonte melhorada de água potável situava-se em $49 \%$, todavia embora esta proporção tenha ascendido aos $63 \% \mathrm{em}$ 2011, estão ainda longe dos 75\% necessários para cumprir-se com as metas relacionadas com os objectivos de desenvolvimento do milénio para 2015. ${ }^{6}$ Por outro lado a África do norte apresenta uma taxa de cobertura quanto a população que utiliza fontes melhoradas de água potável em 2011 em cerca de 92\%, quando em 1990 representava já cerca de $87 \%$ (OMS-UNICEF 2013).

Quadro 3. Evolução da cobertura de água potável em diferentes regiões em desenvolvimento e no mundo (1990-2011)

\begin{tabular}{l|l|l|l|l|l|l}
\hline \multirow{2}{*}{ Regiões } & \multicolumn{3}{|c|}{1990} & \multicolumn{3}{c}{$\mathbf{2 0 1 1}$} \\
\cline { 2 - 7 } & $\begin{array}{l}\text { Água por } \\
\text { conexão } \\
\text { domiciliar }\end{array}$ & $\begin{array}{l}\text { Outras } \\
\text { fontes } \\
\text { melhoradas }\end{array}$ & $\begin{array}{l}\text { Fontes } \\
\text { não } \\
\text { melhoradas }\end{array}$ & $\begin{array}{l}\text { Água por } \\
\text { conexão } \\
\text { domiciliária }\end{array}$ & $\begin{array}{l}\text { Outras } \\
\text { fontes } \\
\text { melhoradas }\end{array}$ & $\begin{array}{l}\text { Fontes } \\
\text { não } \\
\text { melhoradas }\end{array}$ \\
\hline $\begin{array}{l}\text { África } \\
\text { Subsa- } \\
\text { hariana }\end{array}$ & $15 \%$ & $34 \%$ & $27 \%$ & $15 \%$ & $48 \%$ & $24 \%$ \\
$\begin{array}{l}\text { África } \\
\begin{array}{l}\text { Septen- } \\
\text { trional }\end{array}\end{array}$ & $58 \%$ & $29 \%$ & $11 \%$ & $83 \%$ & $9 \%$ & $6 \%$ \\
\hline
\end{tabular}

Fonte: UNICEF (2013)

6 Dos 53 países africanos apenas 26 cumprirão o objectivo do milénio respeitante a redução para a metade das pessoas sem acesso a água potável. Quanto ao saneamento, apenas 5 dos 53 poderão cumprir com a meta relacionada com a redução para a metade a população sem acesso ao saneamento adequado 
No tocante ao saneamento e comparando as duas grandes subregiões, a África subsaariana é também a mais problemática, pois entre 1990 a 2011 apenas registou uma melhoria em 4 pontos percentuais, pois se em 1990 a população com instalações de saneamento adequado era de 26\%, em 2011 representava 30\%. Enquanto a África do norte registou uma evolução de $72 \%$ em 1990 para 90\% em 2011. A tabela abaixo ilustra estas constatações acabadas de referir.

Quadro 4. Evolução da cobertura do saneamento nas diferentes regiões em desenvolvimento e no mundo (1990-2011)

\begin{tabular}{l|l|l|l|l|l|l}
\hline \multirow{2}{*}{ Regiões } & \multicolumn{3}{|c|}{1990} & \multicolumn{3}{c}{$\mathbf{2 0 1 1}$} \\
\cline { 2 - 7 } & $\begin{array}{l}\text { Instalações } \\
\text { melhoradas }\end{array}$ & $\begin{array}{l}\text { Instalações } \\
\text { não } \\
\text { melhoradas }\end{array}$ & $\begin{array}{l}\text { Defecação } \\
\text { ao ar livre }\end{array}$ & $\begin{array}{l}\text { Instalações } \\
\text { melhoradas }\end{array}$ & $\begin{array}{l}\text { Instalações } \\
\text { não } \\
\text { melhoradas }\end{array}$ & $\begin{array}{l}\text { Defecação } \\
\text { ao ar livre }\end{array}$ \\
\hline $\begin{array}{l}\text { África } \\
\text { Subsa- } \\
\text { hariana }\end{array}$ & $26 \%$ & $24 \%$ & $36 \%$ & $30 \%$ & $26 \%$ & $29 \%$ \\
$\begin{array}{l}\text { África } \\
\text { Septen- } \\
\text { trional }\end{array}$ & $72 \%$ & $7 \%$ & $16 \%$ & $90 \%$ & $0 \%$ & $4 \%$ \\
\hline
\end{tabular}

Fonte: UNICEF (2013)

\subsection{Indicadores de cobertura no acesso a água e ao sane- amento no âmbito da SADC}

A região da $\operatorname{SADC}^{7}$ é rica em bacias hidrográficas partilhadas entre diferentes países. Entre as mais importantes destacam-se as bacias do Congo, Zambeze, Limpopo, Orange-Senqu, Okavango e Cunene. Em concreto Angola partilha cinco Bacias com outros países da região e não só. Constata-se bastantes assimetrias no interior da região, segundo os dados, Angola possui a segunda maior disponibilidade de água renovável anual da região $\left(140 \mathrm{~km}^{3}\right)$, todavia o forte crescimento demográfico do país, cerca de $3,3 \%$ poderá exercer uma

7 A Comunidade de Desenvovimento da África Austral (SADC) foi criada em Agosto de 1992, como resultado da transformação da anterior estrutura, a sADCC, que havia sido constituída em 1980. Entre os objetivos da organização destacamse o de promover o desenvolvimento económico entre os estados membros mediante políticas coordenadas de ajuda entre eles. Compõem a organização os seguintes países: Angola, Botswana, República Democrática do Congo, Lesotho, Malawi, Moçambique, Namíbia, Tanzânia, Zimbabwe, Maurícias, República da África do Sul, Suazilândia e Seycheles. 
pressão sobre os recursos hídricos, sobretudo a partir de 2025 data que as projecções demográficas apontam para a existência de uma população acima dos 22 milhões de pessoas (INE - ANGOLA 2012).

As disponibilidades naturais da água entre os países da SADC não se reflectem nos níveis de cobertura dos serviços de abastecimento de água dos países da região, pois na Tabela 3 pode-se constatar que Angola, apesar do seu potencial de disponibilidade na região, encontra-se entre os países que registam os mais baixos padrões de cobertura de água. Os dados apontam que as disponibilidades hídricas no conjunto dos países da região, vêm registando uma evolução negativa nos últimos anos, pois, se em 1995 os $1784.8 \mathrm{~km}^{3}$ de recursos hídricos anuais renováveis serviam teoricamente para 175,8 milhões de pessoas, em 2025 teria que chegar para uma população projectada a volta dos 327.5 milhões (SADC et al, 2002).

Quadro 5. Uso de fontes de água na SADC (\% da população)

\begin{tabular}{|c|c|c|c|c|c|c|c|}
\hline \multirow[t]{2}{*}{ País } & \multirow[t]{2}{*}{ Ano } & \multicolumn{2}{|c|}{ Zonas Urbanas } & \multicolumn{2}{|c|}{ Zonas Rurais } & \multicolumn{2}{|c|}{ Total Nacional } \\
\hline & & $\begin{array}{l}\text { Fontes } \\
\text { melhoradas }\end{array}$ & $\begin{array}{l}\text { Fontes não } \\
\text { melhoradas }\end{array}$ & $\begin{array}{l}\text { Fontes } \\
\text { melhoradas }\end{array}$ & $\begin{array}{l}\text { Fontes não } \\
\text { melhoradas }\end{array}$ & \begin{tabular}{|l|} 
Fontes \\
melhoradas
\end{tabular} & $\begin{array}{l}\text { Fontes não } \\
\text { melhoradas }\end{array}$ \\
\hline Angola & \begin{tabular}{l|}
1990 \\
2011
\end{tabular} & $\begin{array}{l}43 \\
66\end{array}$ & $\begin{array}{l}\mathbf{5 7} \\
\mathbf{3 4} \\
\end{array}$ & $\begin{array}{l}42 \\
35\end{array}$ & $\begin{array}{l}\mathbf{5 8} \\
\mathbf{6 5} \\
\end{array}$ & \begin{tabular}{|l|}
42 \\
53 \\
\end{tabular} & $\begin{array}{l}\mathbf{5 8} \\
\mathbf{4 7} \\
\end{array}$ \\
\hline Botswana & \begin{tabular}{|l|}
1990 \\
2011 \\
\end{tabular} & $\begin{array}{l}100 \\
99 \\
\end{array}$ & $\begin{array}{l}0 \\
1 \\
\end{array}$ & $\begin{array}{l}86 \\
93 \\
\end{array}$ & $\begin{array}{l}14 \\
7\end{array}$ & $\begin{array}{l}92 \\
97\end{array}$ & $\begin{array}{l}8 \\
3 \\
\end{array}$ \\
\hline Lesoto & \begin{tabular}{|l|}
2000 \\
2011 \\
\end{tabular} & $\begin{array}{l}95 \\
91 \\
\end{array}$ & $\begin{array}{l}5 \\
9 \\
\end{array}$ & $\begin{array}{l}78 \\
73\end{array}$ & $\begin{array}{l}22 \\
27\end{array}$ & $\begin{array}{l}80 \\
78 \\
\end{array}$ & $\begin{array}{l}20 \\
22\end{array}$ \\
\hline Malawi & \begin{tabular}{|l|}
1990 \\
2011 \\
\end{tabular} & $\begin{array}{l}91 \\
95\end{array}$ & $\begin{array}{l}9 \\
5 \\
\end{array}$ & $\begin{array}{l}35 \\
82 \\
\end{array}$ & $\begin{array}{l}65 \\
18 \\
\end{array}$ & $\begin{array}{l}42 \\
84\end{array}$ & $\begin{array}{l}58 \\
16\end{array}$ \\
\hline Mozambique & $\begin{array}{l}1990 \\
2011\end{array}$ & $\begin{array}{l}73 \\
78\end{array}$ & $\begin{array}{l}27 \\
22\end{array}$ & $\begin{array}{l}24 \\
33 \\
\end{array}$ & $\begin{array}{l}76 \\
67\end{array}$ & $\begin{array}{l}34 \\
47\end{array}$ & $\begin{array}{l}66 \\
53\end{array}$ \\
\hline Maurício & \begin{tabular}{|l|}
1990 \\
2011 \\
\end{tabular} & $\begin{array}{l}100 \\
100\end{array}$ & $\begin{array}{l} \\
0 \\
\end{array}$ & $\begin{array}{l}99 \\
100 \\
\end{array}$ & \begin{tabular}{|l}
1 \\
0 \\
\end{tabular} & $\begin{array}{l}99 \\
100 \\
\end{array}$ & $\begin{array}{l}1 \\
0\end{array}$ \\
\hline Namíbia & \begin{tabular}{|l|}
1990 \\
2011
\end{tabular} & $\begin{array}{l}99 \\
99 \\
\end{array}$ & $\begin{array}{l}1 \\
1 \\
\end{array}$ & $\begin{array}{l}51 \\
90 \\
\end{array}$ & $\begin{array}{l}49 \\
10 \\
\end{array}$ & $\begin{array}{l}64 \\
93 \\
\end{array}$ & $\begin{array}{l}36 \\
7 \\
\end{array}$ \\
\hline R.D.C & \begin{tabular}{|l|}
1990 \\
2011
\end{tabular} & $\begin{array}{l}88 \\
80\end{array}$ & \begin{tabular}{|l|}
12 \\
20
\end{tabular} & $\begin{array}{l}26 \\
29\end{array}$ & $\begin{array}{l}74 \\
71\end{array}$ & $\begin{array}{l}43 \\
46\end{array}$ & $\begin{array}{l}57 \\
54\end{array}$ \\
\hline Swazilândia & \begin{tabular}{|l|}
1990 \\
2011
\end{tabular} & $\begin{array}{l}86 \\
93\end{array}$ & $\begin{array}{l}14 \\
7 \\
\end{array}$ & $\begin{array}{l}25 \\
67\end{array}$ & $\begin{array}{l}75 \\
33 \\
\end{array}$ & $\begin{array}{l}39 \\
72\end{array}$ & $\begin{array}{l}61 \\
28\end{array}$ \\
\hline Seychelles & \begin{tabular}{l|}
1990 \\
2011
\end{tabular} & $\begin{array}{l}- \\
-- \\
\end{array}$ & -- & $\begin{array}{l}- \\
-- \\
\end{array}$ & $\begin{array}{l}- \\
-- \\
\end{array}$ & $\begin{array}{l}96 \\
96 \\
\end{array}$ & $\begin{array}{l}4 \\
4 \\
\end{array}$ \\
\hline África do Sul & $\begin{array}{l}1990 \\
2011\end{array}$ & $\begin{array}{l}98 \\
99\end{array}$ & $\begin{array}{l}2 \\
1\end{array}$ & $\begin{array}{l}66 \\
79\end{array}$ & $\begin{array}{l}34 \\
21\end{array}$ & $\begin{array}{l}83 \\
91\end{array}$ & $\begin{array}{l}17 \\
9\end{array}$ \\
\hline Zâmbia & $\begin{array}{l}1990 \\
2011\end{array}$ & $\begin{array}{l}89 \\
86\end{array}$ & $\begin{array}{l}11 \\
14 \\
\end{array}$ & $\begin{array}{l}22 \\
50\end{array}$ & $\begin{array}{l}78 \\
50\end{array}$ & $\begin{array}{l}48 \\
64\end{array}$ & $\begin{array}{l}52 \\
36\end{array}$ \\
\hline Zimbabwe & \begin{tabular}{|l|}
1990 \\
2011
\end{tabular} & $\begin{array}{l}100 \\
97\end{array}$ & $\begin{array}{l} \\
3\end{array}$ & $\begin{array}{l}71 \\
69\end{array}$ & $\begin{array}{l}29 \\
31\end{array}$ & $\begin{array}{l}79 \\
80\end{array}$ & $\begin{array}{l}21 \\
20\end{array}$ \\
\hline
\end{tabular}

Fonte: Elaboração própria em base a dados da oMs-UNICEF (2013) 


\section{O Plano Nacional de Águas de Angola}

Angola não é um país com uma larga tradição de Política Hidráulica. As primeiras tentativas de estabelecimento de uma política hidráulica no país tiveram lugar nos últimos 20 anos do final do regime colonial, ou seja, entre os anos 50 do século xx.

Na memória colectiva de muitas sociedades, água e civilização, com as suas conotações sociopolíticas e socioculturais têm andando juntas. A água tem sido objecto de jurisdição e requer ser regulada, repartida com espírito de justiça (Pérez-Díaz, Mezo e Alvarez-Miranda 1996). Em Angola nem sempre foi assim, pois a primeira lei de águas depois da independência surge em 2002, a Lei 06/02.

No mundo ocidental, a tradição de política hidráulica foi fruto do surgimento de uma tradição de pensamento e de acção onde se combinam pelo menos três tradições específicas (PÉrez-DíAz, MEzo e Alvarez-Miranda 1996):

Em primeiro lugar, uma tradição de uma classe política que pretende justificar-se mediante a criação de um Estado cuja legitimidade depende em parte, de sua capacidade para resolver problemas importantes como o da captação, regulação e distribuição de água. Em segundo lugar, o aparecimento e fortalecimento das instituições da sociedade civil, que possibilitaram a mudança do status das pessoas passando de «súbditos» a «cidadãos» e por último, a tradição de um corpo de profissionais, particularmente Engenheiros e sua vocação de contribuir com o seu saber técnico-científico a uma transformação da economia e da sociedade.

Em Angola, durante o período do sistema político monopartidario (1975-1990), os propósitos do modelo de gestão baseavam-se em um aumento constante da oferta sob fórmulas jurídicas pouco claras e em certos casos inexistentes. O Estado encarregava-se mediante o Orçamento Geral do Estado, de todo o financiamento das infraestruturas hidráulicas, embora existindo algumas obras financiadas por organismos internacionais, subvencionando desta forma aos usuários e respondendo a natureza de um regime de matriz socialistamarxista (toda a água pertence ao Estado).

A divisão de competências em matéria de política hidráulica repousava na responsabilidade básica da administração central, cuja actuação articulava-se com a dos governos provinciais (Comissariados províncias e municipais), embora estes organismos estivessem relegados às tarefas de abastecimento público e do saneamento, pois, 
a gestão e administração dos recursos hídricos encarregava-se o governo central.

A política da água em Angola, baseia-se (assim tem sido desde a independência) em um modelo de gestão da oferta, ${ }^{\mathbf{8}}$ cuja preocupação crescente, é aumentar a capacidade da oferta através de investimentos para melhoria da rede de captação e de distribuição ao definir-se o problema da água como sendo um problema de deficit generalizado. Por outro lado, o reconhecimento sobre o valor económico da água e como tal a sua concepção como um bem económico, até agora está só no plano formal, pois, embora a Lei de Águas (Art. ${ }^{\circ}$ 9) assim o considere, na prática segue prevalecendo o paradigma existente na época monopartidaria, seja por limitações na capacidade da oferta ou seja por questões culturais e sociais.

Ademais do elemento anteriormente referenciado, a política de água em Angola apresenta os seguintes elementos ou características básicas:

1) Aumento contínuo e sistemático dos sistemas de água (sistemas aqui nos referimos aos grandes sistemas de captação de água a partir do rio, mas também aos pequenos sistemas como poços com bomba e chafarizes e os sistemas de distribuição) cujo objectivo é aumentar a oferta;

2) Reconhecimento por parte do governo de alta demanda de água;

3) Inexistência de concessões e licenças a operadores privados (se prevê em um futuro breve, pois, foram aprovados em Fevereiro de 2014, os Regulamentos que permitirão a entrada de operadores privados nos serviços de abastecimento de água e saneamento das águas residuais);

4) Baixa eficiência nas redes de distribuição urbana (as perdas tanto técnicas como as comerciais chegam actualmente aos 50\% pelo menos ao nível das duas unidades de estudo por nos analisadas, ou seja Luanda e Benguela). O objectivo do governo plasmado no Plano de 2004-2016 é baixar essas perdas e situa-las em torno aos $25 \% .^{9}$

8 Na base da tipologia de classificação dos modelos de gestão da água, existe ainda o modelo de controlo da demanda e o modelo de uso sustentável (BEL, FAgEda e Mur 2010).

9 «Estratégia de desenvolvimento do sector das águas» é um programa orientador do governo aprovado em 2004. Entretanto, note-se que a nível internacional considera-se que uma rede está bem administrada quando as perdas situam-se abaixo de 15\% (ARoJo e NAREdo 1997). 
5) Baixa correlação entre o preço pago pela água e os seus custos reais (alto nível de subvenções públicas);

6) Baixo nível de depuração das águas residuais urbanas (as redes de esgotos na maioria das províncias está em estado obsoleto (rede colonial que abarca apenas o casco urbano antigo). Actualmente, apenas Luanda e Benguela contam com uma estação de tratamento de águas residuais;

7) Fraca capacidade de gestão da água como resultado das debilidades institucionais;

8) Insuficiência de instrumentos de regulação e inexistência de um órgão regulador do serviço;

9) Sistema tarifário desactualizado.

O quadro seguinte descreve os diferentes modelos de gestão da água, onde se pode ver as principais características do modelo de oferta que constitui o modelo caracterizador da nossa política de água.

Quadro 6. Modelos de Política de Gestão de Água

\begin{tabular}{|c|c|c|}
\hline Modelo & Instrumento da política & Objectivos \\
\hline $\begin{array}{l}\text { Modelo de } \\
\text { oferta }\end{array}$ & $\begin{array}{l}\text { - Políticas de expansão da oferta } \\
\text { - A Administração Pública e a promotora } \\
\text { das infraestructuras hidráulicas }\end{array}$ & $\begin{array}{l}\text { - Consumos unitários } \\
\text { muito altos }\end{array}$ \\
\hline $\begin{array}{l}\text { Modelo de } \\
\text { demanda }\end{array}$ & $\begin{array}{l}\text { - Preços muito baixos ou nulos } \\
\text { - Políticas de Gestão da demanda } \\
\text { - Os preços devem reflectir a escassez } \\
\text { - Maior papel do mercado }\end{array}$ & $\begin{array}{l}\text { - Consumos unitários } \\
\text { mais reduzidos }\end{array}$ \\
\hline $\begin{array}{l}\text { Modelo de uso } \\
\text { sustentável }\end{array}$ & $\begin{array}{l}\text { - A Administraçao Pública prioriza } \\
\text { os objetivos de qualidade } \\
\text { - Os preços refletem a escassez e os } \\
\text { danos produzidos ao Meio Ambiente. }\end{array}$ & $\begin{array}{l}\text { - Sustentabilidade } \\
\text { ambiental }\end{array}$ \\
\hline
\end{tabular}

Fonte: Elaboração própria, adaptado de Xavier P. Alifonso (2007)

\section{O marco da análise comparativa, como base para a compreensão da política hídrica em Angola: Os casos de Luanda e Benguela.}

A análise comparativa entre as duas unidades estudadas no nosso trabalho, proporcionou-nos a identificação de certas analogias ou paralelismos tanto em parâmetros geoclimáticos como inclusive em alguns aspectos referente ao modelo de gestão e na disponibilidade de 
caudais, portanto desde o ponto de vista hídrico, as duas províncias têm abundantes recursos tanto em água superficial quanto subterrâneas, embora com respeito as últimas Benguela representa relativa vantagem. ${ }^{10}$ Mas também constatamos certas diferenças básicas.

A história hidráulica de ambas províncias foi resultado de um mesmo processo, a existência de infra-estruturas hidráulicas remonta a época da colonização. A guerra civil que assolou o país provocou a destruição de parte das infra-estruturas dos sistemas de água, sobretudo em Benguela e limitou também o nível de investimento no sector das águas no país em geral. Paradoxalmente o processo de recuperação dos sistemas de água foi mais rápido em Benguela (actualmente tem em funcionamento 99\% do total dos seus sistemas) contra 61\% de Luanda (SISAS 2013). ${ }^{11}$

Em relação aos volumes de produção e capacidade de rendimento dos sistemas para atender a demanda de água, em ambos casos a capacidade actual não cobre as necessidades existentes, pois, para o caso de Luanda, a capacidade de produção de água actualmente de $488800 \mathrm{~m}^{3} /$ dia, necessita um aumento de $100 \%$ na sua capacidade para cobrir a demanda, segundo reconhecimento do próprio Ministro da Energia e Águas quando textualmente assegurava que «Luanda neste momento tem um nível de cobertura de cerca de 50\%, o seja, os sistemas de água potável, deve permitir, segundo nossa estimativas, cobrir 50\% das necessidades de Luanda, de forma que está planificada a construção de dois novos sistemas, o Bita e o Kilonga Grande, com captação no rio Cuanza, que vão permitir duplicar a capacidade actual. Portanto vamos ter um milhão de metros cúbicos, o que deverá ser suficiente para a população actualmente existente $[\ldots]^{12}$

Benguela conta com uma capacidade actual dos sistemas de água a volta dos $130205 \mathrm{~m}^{3} /$ dia. Embora igualmente não satisfazer as necessidades actuais, todavia ao contrário de Luanda (que necessita duplicar a sua capacidade), Benguela necessita de um aumento na produção de cerca de $37,7 \%$ (o equivalente a $49158 \mathrm{~m}^{3} /$ dia).

10 A maioria dos recursos hídricos subterrâneos encontram-se ao sudeste do país e Benguela abarca $7 \%$ do mesmo.

11 Em termos numéricos, significa que Benguela dos 415 sistemas de agua, estão em funcionamento 411, enquanto Luanda com 36 sistemas, actualmente funcionam 22.

12 Entrevista exclusiva concedida a Agência de Notícias de Angola (ANGOP), pelo Ministro João Baptista Borges, a 31 de Dezembro de 2013. 
A que se deve o maior rendimento dos sistemas de água de Benguela com relação aos de Luanda? É uma questão interessante de analisar, todavia o nosso estudo revela que o maior rendimento dos sistemas de água de Benguela não se podem atribuir aos níveis de investimento no sector, pois, Luanda possui uma carteira de investimentos maior. ${ }^{13}$ Os factores explicativos se podem encontrar na maneira de gerir os investimentos, sobretudo na transparência no processo de contratação pública das empresas que se encarregam dos serviços de manutenção e construção das infra-estruturas hidráulicas.

Em relação ao nível de consumo per capita real, encontramos notáveis diferenças, pois, enquanto Benguela regista um nível de consumo próximos dos 150 litros/pessoa/dia nas zonas urbanas e cerca de 35 litros/pessoa/dia nas zonas per urbanas, Luanda regista 65 litros/pessoa/dia nas zonas urbanas e menos de 20 litros nas zonas per urbanas (PNEIA 2012). ${ }^{\mathbf{1 4}}$

Com relação aos níveis da demanda, há que ter-se em conta que Luanda vive uma maior pressão sobre os recursos hídricos, a julgar pelo indicador demográfico. No entanto o facto de que Benguela tenha a sua estrutura demográfica quase dividida á metade entre população urbana e rural, torna o problema do abastecimento de água potável complexo, dadas as particularidades das zonas rurais em termos de desenvolvimento estrutural por um lado, e sendo a economia da província de Benguela significativamente agrícola por outro, temos uma demanda de água não menosprezável embora em usos diferentes.

Os contrastes entre recursos hídricos disponíveis, nível da demanda e população nas duas províncias, revelam que em geral o nível de cobertura dos abastecimentos urbanos de água potável em Luanda está em 51,5\% contra 46\% de Benguela (IBEP 2008-2009). Todavia esta diferença não é reveladora de uma maior eficácia das estruturas de gestão de água na capital do país (Luanda); corresponde melhor as diferenças estruturais de fundo que têm que ver com maior desenvolvimento socioeconómico de Luanda traduzido em um maior grau

13 No Plano de investimentos de curto e médio prazo, estabelecidos no programa de desenvolvimento do sector das águas (2004-2007) e (2007-2016), para Luanda destinaram-se um orçamento total de cerca de 90 milhões de dólares americanos para investir na primeira etapa, enquanto para Benguela destinaram-se para o mesmo periodo cerca de 87,50 milhões de usD.

14 De acordo com a Organização Mundial da Saúde (oms), são necessários entre 50 e 100 litros/pessoa/dia para garantir que sejam cobertas as necessidades básicas (beber, cozinhar, limpeza da casa e higiene pessoal). 
de urbanização. Isto justifica-se ademais quando comparamos a situação dos abastecimentos de água mediante conexão domiciliária (que é o parâmetro mais elevado e objectivo central de uma política de abastecimento de água as populações), Benguela vive uma situação melhor já que 17,2\% de sua população está servida mediante essa fonte de abastecimento de água, contra os $16 \%$ de Luanda. $\mathrm{O}$ que significa que a maioria da população urbana de Luanda é abastecida mediante conexões públicas partilhada entre os vizinhos, por chafarizes e camiões cisternas (esta ultima que é classificada como fonte não apropriada).

O abastecimento directo mediante fontes superficiais como rio, lago ou outro tipo de nascente (mais comum nas zonas rurais) é maioritariamente usado como principal fonte de abastecimento de água por cerca de 36,1\% da população de Benguela, dado seu elevado nível de carácter rural da sua população, ao contrário de Luanda, onde apenas $1,4 \%$ da sua população utiliza este tipo de fonte.

Por último, consideramos que os elementos aludidos nos parágrafos anteriores revelam que para além das diferenças nos mecanismos e nas estruturas de gestão de água nas duas províncias, há outros factores estruturais de fundo que explicam as diferenças aludidas anteriormente.

\section{Conclusões}

Angola é um dos países africanos com uma rede hidrográfica rica e muito diversificada, mas a cobertura do serviço de água e saneamento situa-se por debaixo da média subsaariana. No entanto, reconhecendo ser água um elemento chave para assegurar as condições essenciais para a vida humana, para o desenvolvimento económico e social, ao bem-estar e ao equilíbrio ambiental, a sua gestão vem tendo uma prioridade crescente na agenda do governo de Angola, fundamentalmente desde 2003-2004. A pesar dessa maior atenção ao sector, os dados actuais da cobertura que Angola ostenta, indica que é um dos países da região Austral que não poderá alcançar as metas de desenvolvimento do milénio relativo a água e ao saneamento. ${ }^{\mathbf{1 5}}$

15 Para alcançar a metas dos oDm relativo a água, Angola necessitaria lograr até 2015 como média nacional 65\% de cobertura em água potável e 75\% na cobertura do saneamento. 
Quanto a análise comparativa entre os dois casos ilustrativos, cabe ressaltar que a distribuição relativa aos usos urbanos é maior em Luanda dado que a demanda urbana residencial é muito maior. Não obstante, a maior eficácia nas redes de distribuição se regista em Benguela, pois, conta com maior nível de consumo per capita, maior estabilidade no funcionamento dos sistemas e também uma maior cobertura de água respeitante a população rural. Por outro lado, Luanda apresenta em relação a Benguela um processo de crescimento económico e um desenvolvimento sociodemográfico mais acelerado. A indústria e o sector serviços mantêm uma expectativa de crescimentos animadores, pese a baixa dos preços de petróleo. Tudo isso implicaria em princípio, novas infra-estruturas que permitiriam melhorar a cobertura actual e garantir os consumos futuros imediatos. Nessa base a planificação hidráulica até 2017 inclui a construção de dois grandes novos sistemas de água (Bita e Kilonga Grande) que se enquadram no modelo de gestão da oferta (uma das características da política de água em Angola). Benguela para além da demanda urbana e ao contrário de Luanda, a agricultura é o grande consumidor de água, o que faz com que o predomínio do modelo de oferta na sua planificação hidráulica seja também evidente.

\section{Referências bibliográficas}

Agudo Pedro Arrojo et al.

2005, Lo público y lo privado en la gestión del agua: experiencias y reflexiones para el siglo XXI. Madrid, Ediciones del Oriente y del Mediterraneo.

Arbós X. e Giner S.

1994, La gobernabilidad: Ciudadania y democracia en la encrucijada mundial. Madrid, Siglo xxi de España Editores.

Arias X. C. e Caballero G.

2013, Nuevo institucionalismo: Gobernanza, economia y políticas públicas. Madrid, Centro de Investigación Sociológicas.

Arojo P. e NAREdo J. M.

1997, La gestión del agua en España y California. Bilbao, Bakeaz.

BAILARÓN L.

2002, Gestión de recursos hidricos. Barcelona, Universidad Politécnica de Catalunya. 
Bel G., Fageda X. e Mur M.

2010, «¿Por qué se privatizan servicios en los municipios (pequeños)? Evidencia empirica sobre residuos solidos y agua», Hacienda Pública Española. Revista de Economia Pública, (Madrid), vol. 192, n. ${ }^{0}$ 1, Marzo, pp. 33-58.

BRugué Q. e GoMá R.

1998, Gobiernos locales y políticas públicas. Barcelona, Ariel.

\section{Dewey J.}

1927, The public an its problems. New York, Holt.

Diaz V. P., Mezo J. e Álvarez-Miranda B.

1996, Política y economia del agua en España. Madrid, Circulo de Empresarios.

Diniz A. C.

1991, Angola. Meio físico e potencialidades agrárias. Lisboa, Instituto para a Cooperação Económica.

DIRECÇÃO NACIONAL DAS ÁGUAS (DNA)

2013, Sistemas de abastecimento de água. Boletim Sectorial. Luanda, Direcção Nacional das Águas, Ministério da Energia e Água.

DW-ANGOLA

2013, Modelo comunitário de gestão de água. Luanda, DW - Development Workshop Angola.

DYE T.

1976, Policy analysis. Alabama, University of Alabama Press.

EASB - EMPRESA DE ÁGUA E SANEAMENTO DE BENGUELA

2013, Apresentação institucional e realizações da EASB e EASL. Benguela, Empresa de Água e Saneamento de Benguela.

EPAL - EMPRESA PÚBLICA DE ÁGUA DE LUANDA

2011, Relatório de actividades $4 .^{\circ}$ trimestre de 201O. Luanda, EPAL - Empresa Pública de Água de Luanda.

ESPINO J. A.

1999, Instituciones y economia: Una introducción al neoinstitucionalismo económico. México, Fondo de Cultura Económica.

Esteban A. e Prat N.

2006, Alternativas para la gestión del agua en Cataluña: Una visión desde la perspectiva de la nueva cultura del agua. Bilbao, Bakeaz.

Evans P.

1996, «El Estado como problema y como solución. Desarrollo económico», Revista de Ciencias Sociales (Buenos Aires), vol 35, n. ${ }^{\circ} 140$, pp. 529-562. 
2004, Autonomia e parceria: Estados e transformação industrial. Rio de Janeiro, Universidade Federal de Rio de Janeiro.

Ferreira P. M. e Guimarães S.

2003, "África Austral: a urgencia de um projecto regional», in V. S. Marques, O desafio da água no século XXI. Entre o conflicto e a cooperação. Lisboa, Editorial Notícias.

GOVERNO DE ANGOLA

2004, «Programa de desenvolvimento do sector das águas», Diário da República (Luanda), I Série, n. ${ }^{\circ}$ 47, 11 de Junho.

Groner $\mathrm{S}$.

2005, Avaliação rápida dos recursos hídricos e uso da água em Angola. Luanda, MINEA - Ministério de Energia e Águas; DNA Direcção Nacional de Águas.

HantKe-Domas M. e Jouravlev A.

2011, Lineamientos de política pública para el sector de agua potable y saneamiento. Santiago de Chile, CEPAL - Comisión Económica para América Latina y el Caribe de las Naciones Unidas [«CEPAL: Documentos de proyectos»; 400] .

INE - INSTITUTO NACIONAL DE ESTATÍSTICA

2012, Anuário de estatísticas sociais. Luanda, INE-Instituto Nacional de Estatística.

INE - INSTITUTO NACIONAL DE ESTADÍSTICA ESPAÑA

2008, «Estadísticas e indicadores del agua: La información estadística, instrumento necesario para una mejor gestión del agua», Boletin Informativo (Madrid), n. ${ }^{\circ}$, del Instituto Nacional de Estadística, pp. 1-12.

KELSON M.

1992, «El síndrome del agua es diferente ċqué está pasando con la industria del agua?», in Federico Aguilera Klink, Economia del Agua en España. Madrid, MAPA [ «Serie Estudios»; 69].

Klink F. A. \& AlcÂNTARa V.

1994, De la economia ambiental a la economia ecologica. Barcelona, Icaria Editorial.

Masagué J. B. Andreu 1986, El agua en España. Barcelona, Lunwerg Editores.

Mendes P. E.

2004, Estado actual do conhecimento dos recursos hidricos de Angola. Luanda, Ministério de Energia e Água (MINEA).

MINEA/DNA

2013, «Sistemas de abastecimento de água», Boletim Sectorial (Luanda), n. ${ }^{\circ}$ 1. Ministério de Energia e Âgua, Direcção Nacional de Águas, pp. 1-18. 
MINEA/PNEA

2012, Plano Nacional da Água. Lisboa, СОВA - Consultores de Engenharia e Ambiente.

OMS/UNICEF

2013, Progresos en materia de saneamiento y agua potable. Informe de actualización 2013. Ginebra, Ediciones de la Organización Mundial de la Salud; New York, UNICEF.

2000, Global water supply and sanitation assessment 2000 report. World Health Organization; unicEF; Water Supply \& Sanitation - Collaborative Council.

ONU — ORGANIZAÇÃO DAS NAÇÕES UNIDAS

2013, World population data sheet. New York, United Nations Statistics Division. Disponível em <www.unescapsdd.org/files/ documents/PUB_Datasheet-2013.pdf $>$

2013, Objectivos de Desarrollo del Milenio. Informe de 2013. Prólogo de Ban Ki-moon. Nueva York, onU.

2012, El agua en los objectivos de Desarrollo del Milenio. Informe de 2012. Nueva York, onU - Naciones Unidas.

2009, Africa Water Vision 2025. New York, ONU.

1992, Conferencia de las Naciones Unidas Medio Ambiente y Desarollo (CNUMED). Rio de Janeiro, 3 al 14 de Junio de 1992. New York, ONU.

PNEA

2012, Angola: Programa Nacional Estratégico para Água 2013-2017. Disponível em <Flash_VdAtlas_An-20.02.2013-pdf $>$.

Pereira A.

2007, "A abundancia ilusoria da água em Angola: Desafios ao sistema institucional», Africana Studia - Revista Internacional de Estudos Africanos (Porto), n. ${ }^{\circ}$ 10, pp. 187-201.

Perez D. V.

1995, Gestión del agua urbana. Madrid, Colegio de Ingenieros de Caminos.

Perez-Diaz V., Mezo J. e Alvarez-Miranda B.

1996, Política y economia del agua en España. Madrid, Círculo de Empresários.

Pestana N.

2011, Pobreza, água e saneamento básico. Luanda, Centro de Estudos de Investigação Científica da Universidade Católica de Angola.

PNUD - PROGRAMA DAS NAÇÕES UNIDAS PARA O DESENVOLVIMENTO

2006, Más allá de la escasez: Poder, pobreza y la crisis del agua. 
Nueva York, PNuD. Disponível em <www.choike.org/nuevo/informes/4791.html>

2005, Human Development Report 2005. International cooperation at a crossroads. Aid, trade and security in an unequal world. New York, UNDP - United Nations Development Programme, 372p.

1999, Informe sobre el desarrollo humano. La mundialización con rosto humano. Madrid, Programa de las Naciones Unidas para el Desarollo; Ediciones Mundi-Prensa.

1997, Human Development Reports 1997, New York, Oxford University Press.

PNUMA/IMA

2002, Perspectivas del medio ambiente mundial 2002 Geo3. Pasado, presente y futuro. Madrid, PNUMA - Programa de las Naciones Unidas para el Medio Ambiente/Industria y Medio Ambiente; Ediciones Mundi-Prensa.

1999, Producción más limpia. Un paquete de recursos de capacitación. Paris, PNUMA - Programa de las Naciones Unidas para el Medio Ambiente/Industria y Medio Ambiente.

Prager D.

2006, «Las políticas de precio», Vanguardia Dossier, n. ${ }^{0}$ 21, Octubre-Deciembre, Agua, el desafio del siglo xxi, pp. 52-59.

PROGRAMA

2004, «Programa de desenvolvimento do sector das águas», Diário da República (Luanda), I Série, n. ${ }^{\circ} 47$.

SADC, IUCN, SARDC E IBRD

2002, Defining and mainstreaming environmental sustainability in water resources in southern Africa. Maseru, Ls: SADCSouthern African Development Community; Environnement and Land Management Sector; Southern African Research Documentation Centre (SARDC); Harare, ZW: IUCN ROSA; Washington, DC, World Bank.

SANCHEZ M. P.

2006, Analisis de políticas públicas. Granada, Universidad de Granada.

SCARTASCINI C. e TOMMASI M.

2011, El juego político en America Latina: ¿Cómo se deciden las Políticas Públicas? Bogotá, Mayol Ediciones.

UNESCO - ORGANIZAÇÃO DAS NAÇÕES UNIDAS PARA A EDUCAÇÃO, A CIÊNCIA E A CULTURA

2009, La cuarta edición del informe sobre el desarrollo de los recursos hidricos en el mundo (WWDR 4), 11. ${ }^{\mathrm{a}}$ reunión de ONU - 
Água, celebrada el 15 de Agosto de 2009 en Estocolmo, Suécia. Paris, unesCo, Programa Mundial de Evaluación de los Recursos Hídricos (WWAP).

2003, WWDR1 - «Agua para todos, agua para la vida», 22 Marzo de 2003, Dia Mundial da Água, celebrado durante el 3er Foro Mundial del Água en Kyoto, Japón. Paris, unEsco, Programa Mundial de Evaluación de los Recursos Hídricos (WWAP).

2000, El informe sobre el desarrollo de los recursos hídricos en el mundo. Paris, unesco, Programa Mundial de Evaluación de los Recursos Hídricos (WWAP). Disponível em <www.unesco.org/ new/es/natural-sciences/.../wwdr4-2002>

\title{
UNICEF
}

2011, Informe anual de UNICEF 2010. Periodo compreendido entre el 1 de enero de 2010 y el 31 de deciembren de 2010. Prefácio de Anthony Lake. UNICEF - División de Comunicaciones, Nueva York.

2009, Annual Report 2008. New York, UniceF Publications. 2008, Relatorio sobre a situação de Angola en materia de água e saneamento. Disponível em < https://esa.un.org/.../angola/.../ Angola_Recomendations_for_Changing_the_Instituti...>

Recepção do manuscrito: 24/06/2015

Conclusão da revisão: 30/03/2016

Aceite para publicação: 29/04/2016

Title: Water policy in Angola: Some notes on water supplies in Luanda and Benguela

\begin{abstract}
Water and sanitation are two current issues on the political agenda as two of the many outstanding issues to be resolved in Angola, despite the fact that it has been around 39 years after the proclamation of its independence. The country has an enormous water potential surpassed only by its neighbor, the Democratic Republic of Congo. However, the 27-year civil war that has raged in the country is a factor explaining why water and sanitation remain two of the biggest public and social problems in Angola. The weight of the war factor is not depreciable, it becomes even greater, and almost exclusively, when the explanations come from government offices. However, this factor alone cannot explain the problem in a generalized way, if we take into account, for example, that in Benguela water management is far more efficient than Luanda. Throughout history, human progress has depended on access to water and the capacity of societies to tap their potential as a productive resource. This perennial reality remains current in the world today. But for a large part of humanity - and this holds true for the case of Angola -, as the latest UNDP (United Nations Development Program) reports state, these bases have not yet been established. Angola faces major challenges, given the multiple problems faced by a significant proportion of its population in access to safe drinking water and adequate sanitation, with all the resulting consequences for public health and well being. Based on our doctoral thesis, the present text analyzes the problem of water governance, focusing on two dimensions: urban supply and sanitation. We
\end{abstract}


have attempted to describe and explain the country's water policy (1975-2014), comparing its impact on two of its most important provinces (Luanda and Benguela), which are presented as illustrative units of water policy in Angola. On the one hand, it is concluded that a supply model can characterize the short and still unconsolidated hydraulic Angonan policy. On the other hand, it is concluded that due to different factors the water distribution structures are more efficient in Benguela than in Luanda, although both provinces share the same institutional and legal framework.

Keywords: Water governance, public policies, urban supplies, basic sanitation.

\section{Fernando Paulo Faria}

Politólogo, é Coordenador da «Série Ciência Política» dos Cadernos de Ciências Sociais, Professor Auxiliar, Chefe do Departamento de Ciência Política (DCP) e membro do Conselho científico-pedagógico da Faculdade de Ciências Sociais (FCS) da Universidade Agostinho Neto (UAN). É Doutor em Ciência Política e Administração (2015) pela Universidade de Barcelona (Reino da Espanha) e Mestre em Políticas públicas e sociais (2004) pela Universidade Pompeu Fabra de Barcelona (Reino de Espanha). Publicou O estudo científico da Ciência Política. Abordagens epistemológicas e metodológicas. Luanda, Edições $\mathrm{Mu}-$ lemba; Ramada, Edições Pedago [ «Cadernos de Ciências Sociais: Série Ciência Política»; 2], 2013 (em co-autoria com Miguel Domingos Bembe e Fernando Muquepe); «El problema de las transiciones democráticas en Africa: los casos de Angola, Botsuana, Mozambique, Zimbabue y Sudafrica», Mulemba - Revista Angolana de Ciências Sociais (Luanda), vol. I, n. ${ }^{\circ}$ 1, Maio de 2011, pp. 25-49.

[e-mail: fariafernando@hotmail.com] 